\title{
ERRATUM
}

\section{Factors associated with hospital admission following asthma exacerbations: a systematic review - ERRATUM}

\author{
B.H. Rowe; N. Arrotta; J. Hill; C. Villa-Roel; E. Dennett; M. Harries
}

doi: $10.1017 / \mathrm{cem} .2016 .83$

In the original publication of the CEM 2016 Conference Supplement, the abstract LO046, "Factors associated with hospital admission following asthma exacerbations: a systematic review," was missing the author C. Villa-Roel from the author list. This omission was also present in the Author Index listing.

The CJEM editors regret this error.

\section{REFERENCE}

Rowe BH, Arrotta N, Hill J, Villa-Roel C, Dennett E, Harries M. Factors associated with hospital admission following asthma exacerbations: a systematic review. CFEM 2016; 18(S1):S46. 